\section{6 OPEN ACCESS}

${ }^{1}$ Department of Sports Medicine, Aspetar-Qatar Orthopaedic and Sports Medicine Hospital, Doha, Qatar ${ }^{2}$ Department of Research and Education, Aspetar-Qatar Orthopaedic and Sports Medicine Hospital, Doha, Qatar ${ }^{3}$ Aspetar Hospital, Doha, Qatar

\section{Correspondence toDr} Cristiano EiraleDepartment of Sports Medicine, Aspetar-Qatar Orthopaedic and Sports Medicine Hospital, Doha 29222, Qatar; cristiano.eirale@aspetar.com

Received 8 February 2012 Accepted 19 July 2012 Published Online First 17 August 2012

\title{
Low injury rate strongly correlates with team success in Qatari professional football
}

\author{
Cristiano Eirale, ${ }^{1}$ J L Tol, ${ }^{1}$ Abdulaziz Farooq, ${ }^{2}$ Faten Smiley, ${ }^{1}$ Hakim Chalabi ${ }^{3}$
}

\begin{abstract}
Background Although the incidence of football injuries should relate to team success there is little empirical evidence.

Objective We investigated the relationship between injury incidence and team success in Qatar first-division football clubs.

Methods Using a prospective cohort study design, we captured exposure and injuries in Qatar male elite football for a season. Club performance was measured by total league points, ranking, goal scored, goals conceded and number of matches won, drawn or lost. Results Lower injury incidence was strongly correlated with team ranking position $(r=0.929, p=0.003)$, more games won ( $r=0.883, p=0.008)$, more goals scored $(r=0.893, p=0.007)$, greater goal difference $(r=0.821$, $p=0.003)$ and total points $(r=0.929, p=0.003)$.

Conclusions Lower incidence rate was strongly correlated with team success. Prevention of injuries may contribute to team success.
\end{abstract}

\section{INTRODUCTION}

Two fundamental questions in sport injury studies are which athletes are at risk and how injury incidence affects team success. ${ }^{1}$ Epidemiological studies typically address the first question focusing on injury rate and risk factors ${ }^{2-4}$; however, for coaches and professional league players, it is more practically relevant to determine how injuries can affect team success.

The catchphrase: 'Never change a winning team' highlights this relevance of team success and emphasises the favourable conditions of a noninjured team. Interestingly, only a few football epidemiological studies have focused on the correlation between injury rate and team success, and none of them showed a moderate or strong correlation. ${ }^{5-7}$ The aim of this study was to investigate the correlation between injury incidence and team success in Qatar First-Division clubs.

\section{MATERIALS AND METHODS}

A prospective cohort study of exposure and injuries in Qatar male elite football was carried out between August 2008 and April 2009. At the beginning of the season, we presented the study objective and methods, consisting in a prospective record of individual exposure and injuries for each first team player, to all 10 first-division clubs and all teams joined the study.

A single doctor or physiotherapist for each club recorded data daily on standardised attendance record and injury cards for each player. We followed the consensus on definitions and data collection procedures in studies of football injuries ${ }^{8}$ and recorded only time loss injuries. Players who were already injured at the beginning of the study were included, but that injury was not incorporated into the results; new players recruited during the study period were not included. One investigator (CE) validated the clubs' self-reported injury data by discussing them with the team physician/physiotherapist and by comparing against the injuries seen at the central treating centre-the Aspetar Qatar Orthopaedic and Sport Medicine Hospital. Club performance was measured by total league points, ranking, goal scored, goals conceded and number of matches won, drawn or lost. Ethical approval was granted by the Institutional Human Research Ethics Committee, Aspetar Hospital, Doha, Qatar.

\section{Statistical analysis}

Injury incidence was expressed as a rate per $1000 \mathrm{~h}$ of exposure, and calculated as (number of injuries/ hours of exposure to risk) $\times 1000$. Poisson $95 \%$ CIs were calculated for the incidence rates. ${ }^{9}$ StatsDirect statistical software V.2.7.8 was used. To determine any association between team injuries and success, Spearman's correlation coefficient was calculated for both injury incidence rate and injury severity against measures of team success. A $p<0.05$ was the cut-off used for statistical significance.

\section{RESULTS}

We excluded three teams which did not provide continuous and reliable data. There were 217 time loss injuries from a total exposure of $36205 \mathrm{~h}$ leading to an injury incidence rate of $6.0 / 1000 \mathrm{~h}$ (95\% CI 4.9 to 6.5$)$. Clubs with lower injury incidence showed a strong correlation with higher league position $(\mathrm{r}=0.929, \mathrm{p}=0.003)$, more games won $(r=0.883, p=0.008)$ and more goals scored $(r=0.893, p=0.007$; figure 1$)$, as well as greater goal difference $(\mathrm{r}=0.821, \mathrm{p}=0.003)$ and total points $(r=0.929, p=0.003)$.

However, total days lost due to an injury were not correlated with any of these parameters; team ranking $(\mathrm{r}=-0.250, \mathrm{p}=0.589)$; wins $(\mathrm{r}=-288$, $\mathrm{p}=0.531)$ and goals scored $(\mathrm{r}=-0.071, \mathrm{p}=0.879$; figure 2).

\section{DISCUSSION}

This is the first study describing a strong correlation between lower injury incidence rate and superior team success in professional football. Previous literature on such a correlation has been inconclusive, but one study described a trend towards a better final league ranking and fewer injury days in Icelandic elite clubs. ${ }^{5}$ In a 15 -season study of one French professional football team, injury rate did not correlate with team ranking. ${ }^{6}$ Ekstrand $e t a l^{7}$ 
Figure 1 Injury incidence correlation with team ranking, total wins and goal scored (r: Spearman's rank correlation).
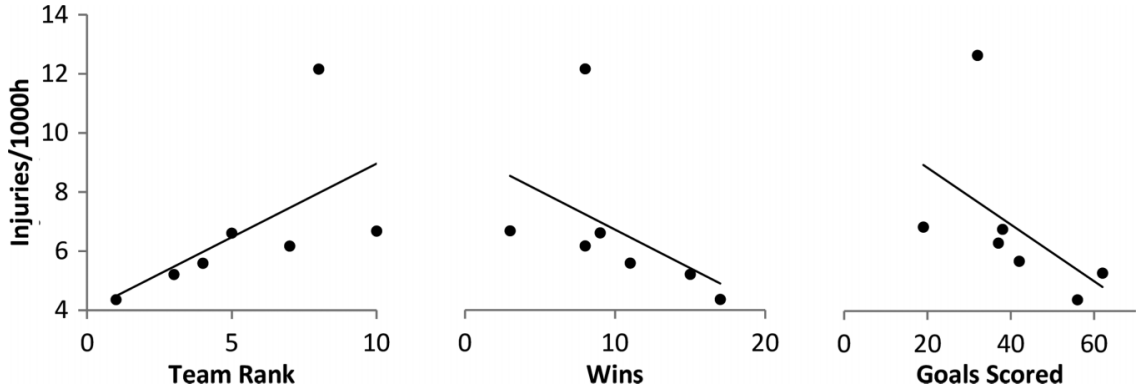

Figure 2 Injury severity correlation with team ranking, total wins and goal scored (r: Spearman's rank correlation).

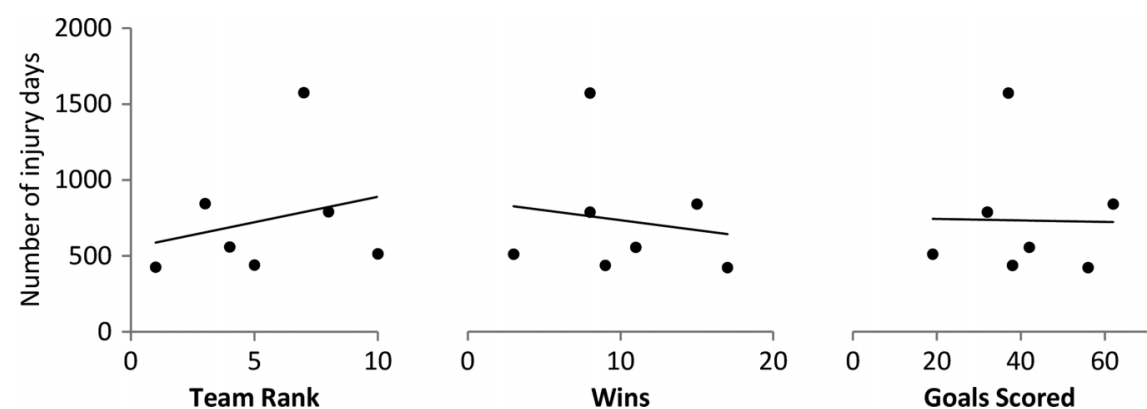

found no association between injury incidence and team success but they reported a correlation between more frequent training and higher ranking; however, they focused on amateur footballers.

The relationship of physical fitness with team as well as individual success has been more extensively proven. A study in the Norwegian elite football league demonstrated higher pre-season VO2max scores from the highest- compared with the lowest-ranking team. ${ }^{10}$ In ice hockey, aerobic capacity was related to individual on-ice performance in the US national firstdivision players. $^{11}$ There was a strong correlation between aerobic capacity (VO2max) and World Cup ranking in alpine skiing. ${ }^{12}$ Several other studies have investigated the relationship between physical condition and individual success, but not any measures of team success.

This study has several limitations. First, we cannot exclude registration bias. Three of the 10 clubs were excluded as outlined above. Second, in the Qatari Football Association, players who have long-term injuries (unable to play $>6$ weeks) can be replaced in the team roster. This may bias our study results, because the replacement player may influence the team's final ranking without being included in the epidemiological study. However, it may also explain the lack of correlation between team success and total injury time loss, which has been previously hypothesised having a direct effect on team success. ${ }^{13}$ However, teams with lower injury incidence could be more successful because of the advantage of having footballers who are familiar with playing together. The team performs harmoniously and with a specific tactical system, supporting the notion to 'never change a winning team'.

Motivation is also a potential consideration in team success. We feel that differences in motivation were unlikely to be a confounding factor in team success in the Qatar Stars League, because there are only 10 teams, as compared with up to 20 in some major national leagues. With this number of teams, most are aiming to win the league, qualify for the Continental cup or avoid relegation.
We note that the number of matches played in the Qatari league is relatively small (compared with English Premier League, La Liga, etc). As frequency of matches is a risk factor for injuries in professional football, ${ }^{14}$ European top teams who play more matches than lower level teams may show an inverse results provoke the hypothesis that an effective medical staff may contribute to team success by implementing evidence-based injury prevention strategies. ${ }^{13}$ This intriguing issue is difficult to study in the real-world setting and thus remains a topic for debate rather than one that can be resolved with data.

Acknowledgements The authors would like to thank all club doctors and physiotherapists in the Qatar Stars League for their participation in the study, as well as the Qatar Football Association and National Sport Medicine Programme for their support.

Competing Interests None.

Patient consent Obtained.

Provenance and peer review Not commissioned; externally peer reviewed.

Open Access This is an Open Access article distributed in accordance with the Creative Commons Attribution Non Commercial (CC BY-NC 3.0) license, which permits others to distribute, remix, adapt, build upon this work non-commercially, and license their derivative works on different terms, provided the original work is properly cited and the use is non-commercial. See: http://creativecommons.org/licenses/by-nc/3.0/

\section{REFERENCES}

1 Finch CF. Getting sports injury prevention on to public health agendas_-addressing the shortfalls in current information sources. Br J Sports Med 2012;46:70-4.

2 Caraffa A, Cerulli G, Projetti M, et al. Prevention of anterior cruciate injuries in soccer. Knee Surg Sports Traumatol Arthrosc 1996:4:19-21.

3 Junge $A$, Rosch MA, Peterson L, et al. Prevention of soccer injuries: a prospective intervention study in youth amateur players. Am J Sports Med 2002;30:652-9.

4 Askling C, Karlsson J, Thorstensson A. Hamstring injury occurrence in elite soccer players after preseason strength training with eccentric overload. Scand J Med Sci Sports 2003;13:244-50.

5 Arnason A, Sigurdsson SB, Gudmundsson A, et al. Risk factors for injuries in football. Am J Sports Med 2004;32:5S-16S.

6 Dauty M, Collon S. Incidence of injuries in French professional soccer players. Int J Sports Med 2011:32:965-9. correlation between injury and team success. Importantly, our 
7 Ekstrand J, Gillquist J, Liljedahl S-O. Prevention of soccer injuries. Am J Sports Med 1983;11:116-20.

8 Fuller CW, Ekstrand J, Junge $A$, et al. Consensus statement on injury definitions and data collection procedures in studies of football (soccer) injuries. Clin I Sport Med 2006;16:97-106.

9 Gail M, Benichou J. Encyclopedia of epidemiologic methods. West Sussex, UK: Wiley, 2000.

10 Wisloff U, Helgerud J, Hoff J. Strength and endurance of elite soccer players. Med Sci Sports Exerc 1998;30:462-7.
11 Green MR, Pivarnik JM, Carrier DP, et al. Relationship between physiological profiles and one-ice performance of a national collegiate athletic association division I hockey team. J Strength Cond Res 2006;20:43-6.

12 Neumayr G. Physical and physiological factors associated with success in professional alpine skiing. Int I Sports Med 2003:24:571-5.

13 Orchard JW. On the value of team medical staff: can the 'Moneyball' approach be applied to injuries in professional football? Br I Sports Med 2009;43:963-5.

14 Dupont G, Nedelec M, McCall A, et al. Effect of 2 soccer matches in a week on physical performance and injury rate. Am J Sports Med 2010;38:1752-8. 